\title{
Epidemiology of Needle-Stick Injuries in Mangalore
}

Dr. Prakash. K. P

1. Assistant Professor, Department of Community Medicine, Kasturba Medical College. Mangalore.

\section{CORRESPONDING AUTHOR:}

Dr. Prakash K.P, Kurubarahalli Patel, PES Medical College,

Kuppam- 517425, AP, India,

Email id-drprakashkp@gmail.com,

Ph- 00919686448868.

\begin{abstract}
:
BACKGROUND: Health care workers (HCWs) are always at greater risk of infection by needlestick injuries (NSIs) owing to their greater handling of sharps in various situations. OBJECTIVE: The main objective was to review the epidemiology of NSIs among HCWs, and describe the circumstances under which these injuries occurred. METHODS: A questionnaire based, cross sectional study was done during the month of January 2008 at 3 Kasturba Medical College (KMC) institutions, Mangalore. The data was computed and analyzed using SPSS statistical package. RESULTS: During the study period 272 HCWs were self administered questionnaire/interviewed and 102 HCWs reported (37.5\%) incidents of injuries with needles during the past 12 months. Doctors were the most frequent victims (64.7\%), followed by waste disposal staff (25.5\%) and Nurses (7.8\%). More than 50\% of the victims had more than 3 pricks in the last 12 months. Hospital wards and operation theatre were the major locations of needlestick incidents (31.4\% each). Most commonly, injuries occurred during suturing $(41.1 \%)$ and when using solid bore or suturing needle (47.1\%). Majority of them neither reported the injury $(60.8 \%)$ nor received post-exposure prophylaxis (70.6\%). Patient tested sero-negative was the major reason for not reporting the injury. Government hospital staff and waste disposal staff had significantly higher chance of NSI when compared to their counterparts. Conclusions: The study re-emphasized the importance of continued educational and prevention programmes for HCWs in the prevention of needle-stick injuries.
\end{abstract}

KEYWORDS: Epidemiology, Needle-stick injuries, Health care workers, Mangalore.

\section{INTRODUCTION:}

Many infections including blood-borne viruses such as Human Immuno-deficiency Virus (HIV), hepatitis B and C can be transmitted by exposure to infected blood or other body fluid via an accidental inoculation injury (1). Health care workers (HCWs) who are exposed to needles during clinical and non-clinical activities are at increased risk of acquiring needle-stick injuries (NSIs) (2).

Accidental NSIs are an occupational hazard for HCWs. According to a global estimation, 16,000 Hepatitis C (HCV), 66,000 Hepatitis B (HBV) and 1000 cases of HIV may have occurred worldwide in the year 2000 among HCWs through their exposure to NSI's (3). In Germany, about 500,000 needle-stick injuries occur annually among HCWs (4). More than 100,000 and 600,000 to 800,000 injuries annually have been reported in UK hospitals and in USA respectively $(5,6)$. About half of these injuries go unreported (7-9,). Data from the EPINet 
system suggest that approximately 28 needle-stick injuries/100 beds/year occur in US hospitals (10).

Hollow-bore needles are most frequently implicated with the transmission of bloodborne pathogens because the blood remaining inside the bore of the needle after use contains a larger volume of organisms than the relatively small amount remaining on the outside of a solid bore needle, such as the suturing needle (11). The activities associated with the majority of NSI include withdrawing blood, recapping of needles, administering injections, inappropriate disposal of needles, and missing the target while attempting to transfer blood or other body fluids from syringes to specimen tubes or culture bottles (12).

Following a NSI with infected blood, transmission of the 3 principal viruses, HIV, HCV and HBV occurs in $0.3,3$ and $30 \%$ of cases, respectively (13). Although the risk of infection following a single NSI is very small, "universal precautions" and immunization against HBV may reduce the risk of injury, infection and illness (14).

In general, only a few studies have been published on NSI from developing countries, (15-17) although more than $90 \%$ of NSI occur in developing countries (18). Published data from India (19-22) and in our institutions are limited, therefore, the present study was undertaken to study the epidemiology of NSI in HCWs in the Kasturba Medical College (KMC) institutions, and describe the circumstances under which these injuries occurred.

\section{MATERIALS AND METHODS:}

The study was conducted in the $3 \mathrm{KMC}$ institutions (KMC Hospital (Attavar), Government Wenlock and Lady Goschen Hospital) in Mangalore. Convenience non-random samples of 372 HCW's were self administered/interviewed using a pretested Performa. The Performa was a self administered questionnaire that was completed by the HCW's. The ancillary staffs were interviewed and the questionnaire was filled by the trained medical students. The assessment of data was done using modified methods established by World Health Organization (WHO) (23).

The study was conducted during the month of January 2008. The target population was HCWs in KMC institutions including doctors (staff, postgraduate students and Inters), nurses, and waste disposal staff. The working definition of needle-stick injuries used was injuries caused by hollow-bore needles such as hypodermic needles, blood collection needles, intravenous (IV) stylets and needles used to connect parts of IV delivery systems (12). Data collected from the Performa include: age, gender, details of the incident which included the type of needlestick device and the circumstances under which the injury occurred. Additionally, questions related to awareness as well as basic steps in management of injuries were also included. The data also included was hepatitis B immune status, HIV and hepatitis B serologic markers, the job category and place of work of the injured HCWs. Prevalence calculation was according to, HCW who had at least 1 NSI during the last 12 months. The data was computed in a Microsoft Excel 5.0 spreadsheet and statistically analyzed using the Statistical Package for the Social Sciences (SPSS Inc, Chicago, IL, USA). Proportions were calculated and chi-square test was used to test the significance and $p$ value $<0.05$ was considered as significant at $95 \%$ confidence interval.

\section{RESULTS:}

A total of 272 HCW's were involved in the study. The basic characteristics of the study population are shown in Table1. Of the 272, majority of them were in the age group of 25-34 
years (51.5\%), females (64\%), doctors (57.4\%) and from KMC, Attavar Hospital (42.6\%). The mean age and standard deviation of study subjects was $32.1 \pm 9.2$ years. Almost $80 \%$ of HCW's had received hepatitis B vaccine, although only $75.3 \%$ had 3 complete doses. Fifty-four persons $(19.8 \%)$ received no immunization.

\section{AWARENESS:}

Nearly, $10 \%$ of the HCWs had no knowledge and $24 \%$ had partial knowledge about the diseases transmitted through needle stick injuries. Approximately, $72 \%$ of them were aware of the presence of written policy. Notably, $24 \%$ of the study subjects were not aware about the correct disposal of sharps.

Approximately 37.5\% (102/272) of the study subjects reported that they had at least one NSI during the last 12 months. Needle-stick injuries and circumstances in which these injuries occurred are depicted in table 2. Doctors were the most frequent victims $(66 / 102$ 64.7\%), followed by waste disposal staff (26/102 - 25.5\%) and Nurses (8/102 - 7.8\%). Proportionately Waste disposal staff (26/42 - 61.9\%), Doctors (66/156 - 42.3\%) and Nurses $(8 / 62-7.8 \%)$ were the most common occupation among the NSI candidates. Alarmingly more than $50 \%$ of the NSI's had more than 3 pricks in the last 12 months. Nearly $63 \%$ of the injuries occurred during suturing or during disposal of sharp objects. Solid bore or suturing needle was the most common device causing the injury (47.1\%). The most common cause of NSI was accidental (45.1\%) (Not preventable) followed by restless patient (17.6\%) and rushed $(11.8 \%)$ or fatigued (11.8\%). Surprisingly $60.8 \%$ of them who had NSI did not report to the authorities even though majority $(80 \%)$ of them said that they would report if they had a NSI and only $29.4 \%$ of the injured received post exposure prophylaxis. The common reason for not reporting the injury was patient tested sero-negative. Only four ( $3 \mathrm{HBV}$ and $1 \mathrm{HIV}$ ) of the patients on whom the needle was used tested positive and in nearly 51\% (52/102) of the patients disease status was not know. Thirty two (31.4\%) of NSI occurred in hospital wards, 32 (31.4\%) in the operation theatre, 18 (17.6\%) in the waste disposal center (figure 1).

Government hospital staff had significantly higher chance of NSI $\left(X^{2}=8.05, p=0.01\right.$, $\mathrm{df}=2$ ) and waste disposal staff had significantly higher chance when compared to their counterparts $\left(\mathrm{X}^{2}=13.9, \mathrm{p}=0.01, \mathrm{df}=2\right)$ (Table 3$)$

\section{DISCUSSION:}

Needle-stick injuries are the most frequent occupational hazard affecting health care workers, and the most life-threatening. This cross sectional study involved a total of 272 study subjects among them 102 needle-stick injuries was reported. In this study the rate of NSIs being 0.42 /doctor/year, 0.13 /nurse/year, 0.62/waste-disposal staff/year was higher when compared to a study in Saudi Arabia (0.06/doctor/year and 0.11/nurse/year) (24) and lesser (0.57 /doctor/year and $0.83 /$ nurse/year) when compared to a study in USA (25).

In our study, 37.5\% (prevalence) of participant HCW's had sustained at least one needlestick injury in the last 12 months, which is comparable to a study in Germany (31.4\%) (4) and in India (34.8\%) (19). However, the reported prevalence was more than double in an Indian study (80.1\%) (26). Twelve months is a long period leading to bias which is a limitation in the study. Nursing assistants are at high risk for NSIs because of their nature of work. Studies from Saudi Arabia (65.8\% and 19.2\%) (24), Ireland (49.5\% and 28.5\%) (27) and in USA (40\% and 28\%) (28) reported that the NSIs were more frequent among nurses than doctors, whereas doctors reported frequent NSIs in Indian studies (19-22) including our study. This is probably because 
in most of the Indian hospitals Junior/Senior resident doctors and Interns are more commonly involved in clinical procedures. This wide variation in prevalence and proportions in various studies could be due to underreporting (7-9), and/or different study methodologies (24). The highest rate (26/42 - 61.9\%) among waste disposal staff can be attributed to unsafe methods of waste disposal and collection.

In this study, hospital wards and operation theatre were the common places of NSIs (31.4\% each). Similar observations were made in Saudi Arabia (45.1\% - hospital wards, 16.9\% OT) and Scotland (53\% - hospital wards, 16\% - OT) (24) (29).

The proportion of medical staff who reported to the authorities after a NSI was $20.0 \%$ in our study. The main reason for not reporting in our study was patient tested sero-negative. Other possible explanation may be that some doctors are inclined to self-assess and not report such injuries, thus contributing to the apparent lower reporting of NSIs (29). Historically, suboptimal (under-reporting) reporting of incidents can introduce bias in studies on selfreported injuries. (30). Some researchers have shown that the rate of under-reporting among doctors, especially among those frequently exposed to HIV-infected blood (31).

Some of the circumstances in which the injuries in various studies occurred are compared in table 4 with the present study.

Continuing medical education (CME) programs for HCWs including health education program for waste disposal staffs need to be conducted by the infection control department to increase the awareness about the prevention and management of NSI's because of proven positive impact of intervention educational programmes (32). Hepatitis B vaccination of all at risk HCWs in our institutions (23.4\% never received). It is recommended by the CDC that all atrisk HCWs be vaccinated against HBV infection (33). When the results of the study were reported to the authorities, they were surprised and promised to take appropriate necessary action.

In conclusion, Needle-stick injuries is a major concern in our institutions especially government hospitals. The study re-emphasized the importance of continued medical educational and prevention programmes for HCWs especially health education for waste disposal staff in the prevention of needle-stick injuries. Mandatory reporting, laboratory testing, post exposure prophylaxis (HBV) are some of the administrative measures (Accidental Inoculation Policy) that needs to be taken to reduce the prevalence of NSIs in our institutions.

\section{ACKNOWLEDGEMENT}

The author is grateful for the assistance of the medical students in conducting the study. All the HCWs who participated in the study and who supported in conducting this study are acknowledged.

\section{CONFLICT OF INTEREST:}

None declared. 
Table1. Socio-demographic characteristics of the study subjects at the KMC institutions, Mangalore. $(\mathrm{N}=272)$

\begin{tabular}{|c|c|c|}
\hline Characteristics & Numbers & Percent (\%) \\
\hline Age: & 46 & 16.9 \\
\hline$<25$ & 140 & 51.5 \\
\hline $25-34$ & 54 & 19.8 \\
\hline $35-44$ & 32 & 11.8 \\
\hline$\geq 45$ & 98 & 36 \\
\hline Gender: & 174 & 64 \\
\hline Male & 116 & \\
\hline Female & 96 & 32.6 \\
\hline Hospital: & 60 & 22.1 \\
\hline KMC, Attavar & 156 & 57.4 \\
\hline Govt. Wenlock & 62 & 22.8 \\
\hline Lady Goschen & 12 & 4.4 \\
\hline Occupation: & 42 & 15.4 \\
\hline Doctors &
\end{tabular}

Table2. Distributions of NSI's according to the circumstances in which the injuries occurred

\begin{tabular}{|l|c|c|}
\hline Situation (N=102) & Numbers & Percent (\%) \\
\hline Injection related & 18 & 17.6 \\
\hline Re-capping needles & 8 & 7.8 \\
\hline Suturing & 42 & 41.1 \\
\hline During disposal & 22 & 21.6 \\
\hline IV-line related, canula & 4 & 4.0 \\
\hline Accidental exposure & 8 & 7.8 \\
\hline Device (N=102) & \multicolumn{2}{|l|}{} \\
\hline Hypodermic needles & 12 & 11.8 \\
\hline Blood collection needles & 12 & 11.8 \\
\hline IV stylets & 6 & 5.9 \\
\hline Sharps related to IV delivery system & 4 & 3.9 \\
\hline Solid bore/suturing needle & 48 & 47.1 \\
\hline Don't know & 20 & 19.6 \\
\hline Cause of injury (N=102) & 12 & 11.8 \\
\hline Rushed
\end{tabular}

Journal of Evolution of Medical and Dental Sciences/Volume1/ Issue3/July-Sept 2012 Page 132 


\begin{tabular}{|l|c|c|}
\hline Fatigued & 12 & 11.8 \\
\hline Lack of skills & 4 & 3.9 \\
\hline Restless patient & 18 & 17.6 \\
\hline Lack of assistance & 10 & 9.8 \\
\hline Not preventable & 46 & 45.1 \\
\hline Reasons for not reporting (N=62) & 0 & 0 \\
\hline It takes too much time & 10 & 16.1 \\
\hline No benefit in reporting & 0 & 0 \\
\hline Did not want to know the results & 0 & 0 \\
\hline Stigma of having had a NSI & 18 & 29 \\
\hline Not mandatory to report & 34 & 54.8 \\
\hline Patient was tested sero-negative & & \\
\hline
\end{tabular}

Table3. Occurrence of needle-stick injuries in 3 different hospitals and among staff

\begin{tabular}{|c|c|c|c|}
\hline Hospital $(\mathrm{N}=102)$ : & Yes & No & $\mathrm{X}^{2}$ \\
\hline KMC, Attavar & 28 & 88 & \multirow{3}{*}{$\begin{array}{c}8.05 \\
p=0.01 \\
d f=2\end{array}$} \\
\hline Govt. Wenlock & 48 & 48 & \\
\hline Lady Goschen & 26 & 34 & \\
\hline \multicolumn{4}{|l|}{ Occupation $(\mathrm{N}=100)$ : } \\
\hline Doctors & 66 & 90 & \multirow{3}{*}{$\begin{array}{c}13.9 \\
\mathrm{p}=0.01 \\
\mathrm{df}=2\end{array}$} \\
\hline Nurses & 8 & 54 & \\
\hline Waste disposal staff & 26 & 16 & \\
\hline
\end{tabular}

Note: Laboratory technicians were excluded in the comparison because only 2of 12 reported NSI

Table4. Comparison of NSI's according to the circumstances in which the injuries occurred

\begin{tabular}{|c|c|c|c|c|c|c|}
\hline REFERENCES & $\begin{array}{c}\text { Present } \\
\text { Study }\end{array}$ & 26 & 24 & 19 & 20 & 21 \\
\hline \multicolumn{7}{|l|}{ Situation } \\
\hline During Suturing & 41.1 & 20.3 & 41.7 & $29.4^{*}$ & $62^{*}$ & $58.1^{*}$ \\
\hline $\begin{array}{l}\text { Recapping } \\
\text { needles }\end{array}$ & 7.8 & 39 & 29 & 30.4 & 6.3 & 14.8 \\
\hline \multicolumn{7}{|l|}{ Device Used } \\
\hline $\begin{array}{l}\text { Solid bore/ } \\
\text { suturing needle }\end{array}$ & 47.1 & 33 & 15.1 & 30.5 & 19.2 & 20.9 \\
\hline \multicolumn{7}{|l|}{ Cause of injury } \\
\hline Restless patient & 17.6 & 12 & 8 & - & - & - \\
\hline Not preventable & 45.1 & - & - & 10.9 & - & - \\
\hline Fatigue & 11.8 & - & - & 50.4 & - & - \\
\hline
\end{tabular}


Note: All the numbers are percentage unless specified

* During clinical procedures including suturing

- Particular information not available

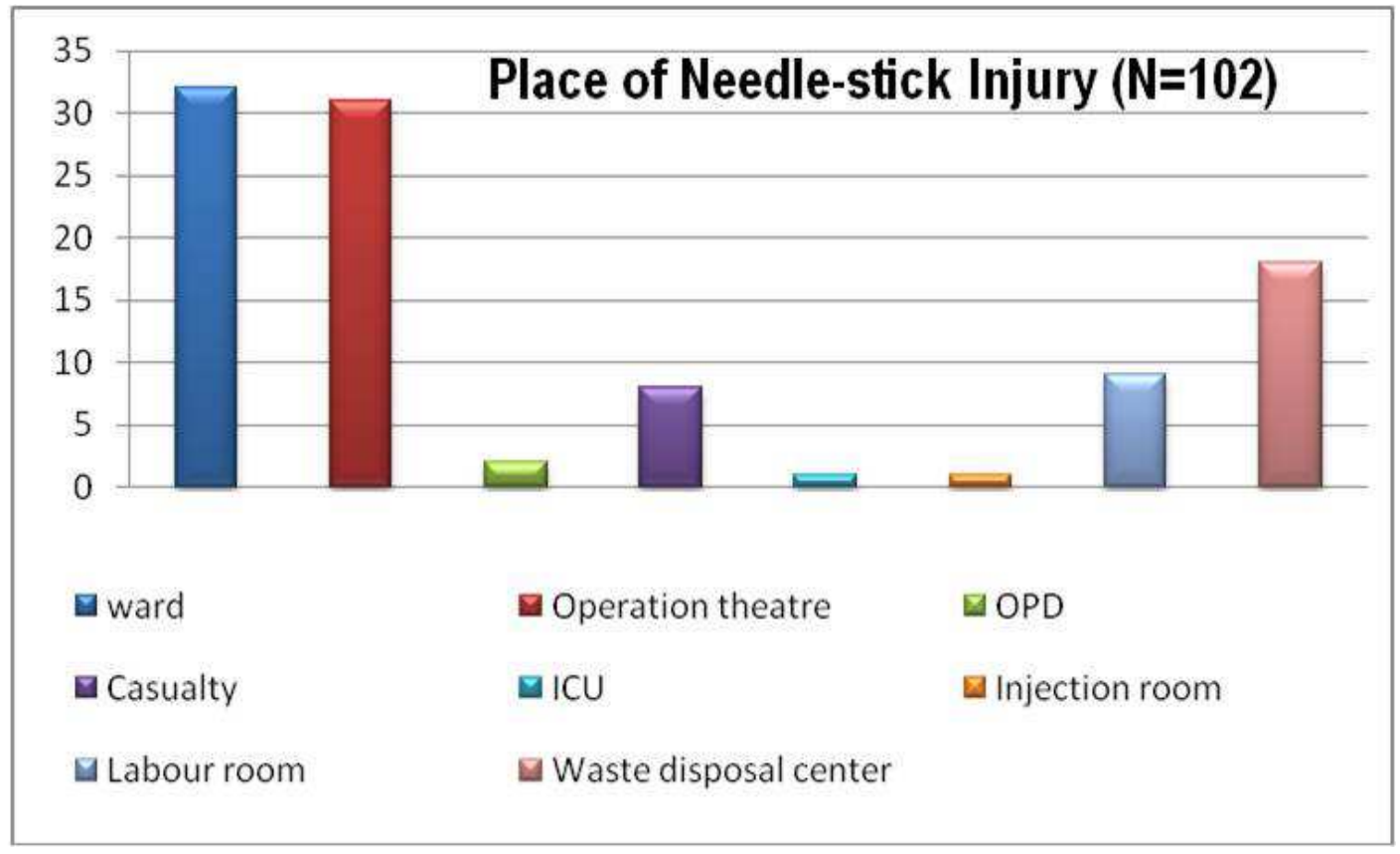

\section{REFERENCES}

1. Parkside Health. Policy for the prevention and management of accidental inoculation injuries.TrustPolicies $200 \quad$ 2001; Page3. Available at http://www.brentpct.nhs.uk/doxpixandgragix/ICC9PolicyforthePreventionandManagementofA ccidentalInoculationInjuries.doc. Accessed on 20-11-2010.

2. Tarantola A, Golliot F, Astagneau P, Fleury L, Brucker G. Blood and Body Fluids Exposure Surveillance Taskforce. Occupational blood and body fluids exposures in HCWs: fouryear surveillance from the Northern France network. Am J Infect Control 2003; 31:357-63.

3. Pruss-Ustun A, Rapiti E, Hutin Y. Estimation of the global burden of disease attributable to contaminated sharps injuries among health-care workers. Am J Ind Med 2005; 48(6):482-90.

4. Wicker S, Jung J, Allwinn R, Gottschalk R, Rabenau HF. Prevalence and prevention of needlestick injuries among health care workers in a German university hospital. Int Arch Occup Environ Health 2008; 81(3):347-54.

5. World Health Organization (WHO). Nursing Matters fact sheets. ICN on Preventing Needlestick Injuries. July 2000. Available from http://www.who.int/occupational health/ activities/2icnneed.pdf Accessed latest on 01-12-2010.

6. Henry K, Campbell S. Needlestick/sharps injuries and HIV exposures among health care workers: national estimates based on a survey of U.S. hospitals. Minn Med 1995; 78:176568.

7. Rodriguez EB, Moruno AJR, Dona JAC, Pujolar AE, Fernandez FJL. Underreporting of percutaneous exposure accidents in a teaching hospital in Spain. Clin Perform Qual Health Care 1999; 7:88-91. 
8. Centers for Disease Control and Prevention (CDC). Evaluation of safety devices for preventing percutaneous injuries among health-care workers during phlebotomy procedures Minneapolis-St.Paul, New York City, and San Francisco, 1993-1995. MMWR 1997; 46(2):21-5.

9. Osborn EHS, Papadakis MA, Gerberding JL. Occupational exposures to body fluids among medical students. A seven year longitudinal study. Ann Intern Med 1999; 130(1):45-51.

10. International Health Care Worker Safety Center, University of Virginia. US. Exposure prevention information network (EPINet) Sharps Injury and Blood and Body Fluid Exposure Surveillance Research Group. Sharps Injury and Blood and Body Fluid Exposure Report for 2007. August 2009. Available from http://www.healthsystem.virginia.edu/internet/epinet/EPINet 2007-rates.pdf Accessed latest on 01-11-2010.

11. Occupational Safety and Health Administration (OSHA). Safer Needle Devices: Protecting Health Care Workers 1997. Available from http://www.thebody.com/content/art5947.html. Accessed latest on 06-12-2010

12. National Institute for Occupational Safety and Health (NIOSH). Preventing needle stick injuries in health care setting. November 1999; Publication No. 2000-108. Available from http://www.cdc.gov/niosh/docs/2000-108/pdfs/2000-108.pdf. Accessed latest on 18-112010.

13. Leasa Benson. Accidental Inoculation Injury - Guidance for healthcare professionals on dealing with needle-stick injuries to members. NHS Manchester Infection Control Committee report, Document Reference CICT001 April 2007; Page 6. Available from http://www.manchester.nhs.uk/document.../AccidentalInnoculationInjuryCommunitySettingN ov08.doc Accessed latest on 8-11-2010.

14. Centers for Disease Control and Prevention (CDC). Universal Precautions for prevention of HIV, HBV and other blood borne pathogens in health care settings. MMWR 1988; 37: 377-88.

15. Gumodoka B, Favot I, Berege ZA, Dolmans WM. Occupational exposure to the risk of HIV and health care workers in Mwanza Region, United Republic of Tanzania. Bull World Health Org 1997; 75: 133-40.

16. Vong S, Perez JF, Sok S, Som S, Goldstein S, Hutin Y, Tulloch J. Rapid assessment of injection practices in Cambodia, 2002. BMC Pub Health 2005; 5: 56-62.

17. Memish ZA, Almuneef M, Dillon J. Epidemiology of needle sticks and sharps injuries in a tertiary care center in Saudi Arabia. Am J Infec Control 2002; 30: 234-41.

18. World Health Organization (WHO). Safe Injection Global Network, Health Care Worker Safety, Aide-Memoire for a Strategy to Protect Health Care Workers from infection from blood borne virus. 2003; WHO/BCT/03.11. Available from http://www.who.int/injection safety/ toolbox/en/AM HCW Safety EN.pdf. Accessed latest on 20-11-2010.

19. Sharma R, Rasania S, Verma A, Singh S. Study of prevalence and response to needle stick injuries among health care workers in a tertiary care hospital in Delhi, India. Indian J Community Med 2010; 35(1):74-7.

20. Salelkar S, Motghare DD, Kulkarni MS, Vaz FS. Study of needle stick injuries among health care workers at a tertiary care hospital. Indian J Public Health. 2010; 54(1):18-20.

21. Jayanth ST, Kirupakaran H, Brahmadathan KN, Gnanaraj L, Kang G. Needle stick injuries in a tertiary care hospital. Indian J Med Microbiol 2009; 27(1):44-7.

22. Rele M, Mathur M, Turbadkar D. Risk of needle stick injuries in health care workers a report. Indian J Med Microbiol. 2002; 20(4):206-7. 
23. World Health Organization (WHO). Injection practices: Rapid assessment and responseguide; $\quad$ October $2002 . \quad$ Available from http://www.who.int/injection safety/toolbox/en/RARG.pdf. Accessed latest on 20-10-2010.

24. Saulat J. Epidemiology of needle-stick injuries among health care workers in a secondary care hospital in Saudi Arabia. Ann Saudi Med 2005; 25(3):233-38.

25. Stotka JL, Wong ES, Williams DS, Stuart CG, Markowitz SM. An analysis of blood and body fluid exposures sustained by house officers, medical students, and nursing personnel on acute-care general medical wards: a prospective study. Infect Control Hosp Epidemiol 1991; 12:583-90.

26. Muralidhar S, Singh PK, Jain RK, Malhotra M, Bala M. Needle stick injuries among health care workers in a tertiary care hospital of India. Indian J Med Res 2010; 131:405-10.

27. O'Connell T, Hayes B. Occupational sharps injuries in a Dublin teaching hospital. Ir Med J. 2005; 96(5): 143-5.

28. Shah SM, Silverstein B, Bonauto D, Foley M, Kalat J. Needlestick Injuries among health care workers in Washington State, 1996-2000. Safety and Health Assessment and Research for Prevention, (SHARP), Washington State Department of Labor and Industries, Technical Report Number 64-04-2003. Available from http://www.lni.wa.gov/Safety/Research/files/Needle Stick.pdf. Accessed latest on 1-12-2010.

29. National Health Services (NHS), Scotland. Needlestick injuries: sharpen your awareness: Report of the Short Life Working Group on needlestick injuries in the NHS Scotland. Available from http://www.scotland.gov.uk/Resource/Doc/158726/0043078.pdf. Accessed latest on 02-12-2010.

30. Hamory BH. Underreporting of needle stick injuries in a university hospital. Am J Infect Control 1983; 11: 174-177.

31. Mangione CM, Gerberding JL, Cummings SR. Occupational exposure to HIV: frequency and rates of under-reporting of percutaneous and mucocutaneous exposure by medical house staff. Am J Med 1991; 90: 85-90.

32. Richard VS, Kenneth J, Ramaprabha P, Kirupakaran H, Chandy GM. Impact of introduction of sharps containers and of education programmes on the pattern of needle stick injuries in a tertiary care centre in India. J Hosp Infect. 2001; 47(2):163-5.

33. Centers for Disease Control and Prevention (CDC). Immunization of health care workers. MMWR 1997; 46 (RR-18): 1-42 